\title{
Shoot and Root Growth and Lysigenous Aerenchyma Formation in Rosetted and Stem-extensional Plants of Eustoma grandiflorum (Raf.) Shinn.
}

\author{
Masataka Yamashita* and Hitoshi Imamura \\ National Agricultural Research Center for Kyushu Okinawa Region, Kurume 839-8503, Japan
}

Influences of rosetting on shoot and root growth, and the inner structure of the stem and root of Eustoma grandiflorum plants were studied. The rosetted and stem-extensional plants, regulated by thermal conditions during ripening in the previous season, were grown under the same conditions. Rosetting was marked by the severe restraint of stem elongation, thickening of stems and leaves, increasing leaf width, thickening of roots, and a change in the growth direction of roots. However, it had less of an effect on the shoot dry matter weight, leaf emergence, auxiliary bud formation, maximum root length, and lateral root formation. Furthermore, little difference was detected between the root dry matter weight of rosetted plants and that of stem-extensional plants, excluding the flowering time when the dry matter weight of the roots of stem-extensional plants tended to decrease. Both rosetted and stem-extensional plants developed lysigenous aerenchyma in the cortex of the roots and stem. This structure could contribute to the marked wetness tolerance of Eustoma grandiflorum.

Key Words: Eustoma grandiflorum, lysigenous aerenchyma, root growth, rosetting, shoot growth.

\section{Introduction}

Eustoma grandiflorum is well known as a plant that shows typical rosettes. Individuals commence stem elongation and enter the reproductive phase with exposure to specified temperatures during the early growth stage: $3^{\circ} \mathrm{C}$ and $10^{\circ} \mathrm{C}$ during germination (Ohkawa et al., 1993), or $11^{\circ} \mathrm{C}$ and $18^{\circ} \mathrm{C}$ in the early stage of growth (Pergola, 1992; Tanigawa et al., 2001). However, they almost cease stem elongation and never enter the reproductive phase without exposure to such temperatures (Harbaugh et al., 1992; Ohkawa, 2003a; Pergola, 1992). Diverse reactions of shoot growth caused by rosetting have been studied in detail (Ohkawa et al., 1991, 1994; Takesaki et al., 2004); however, there have been few studies on the growth reactions of roots and the mutual relationships between shoot and root growth from the viewpoint of rosetting, excluding the general property that the roots grow actively (Ohkawa, 2003b). In addition, seedlings are so tolerant to excess water that the roots sustain no damage even under flood conditions (Imamura and Suto, 1998). This characteristic could be related to the environment in their original habitat (Yashiro, 1993). They could develop a similar structure in roots to adapt to anaerobic conditions as some gramineous plants, such as paddy rice (Kono,

Received; December 26, 2005. Accepted; July 18, 2006.

* Corresponding author (E-mail: my898@affrc.go.jp).
1979; Tatsumi, 1998). But the mechanism in Eustoma grandiflorum has not been identified.

Conventionally, the rosetting or stem-extensibility of plants has been regulated by thermal conditions applied during the raising period of seedlings. This method, however, is problematic because the raising conditions of seedlings can affect subsequent growth. Recently, it was clarified that exposure to a low temperature or the evasion of a high temperature during the ripening period broke rosetting in Eustoma grandiflorum (Imamura et al., 2003; Ohkawa et al., 1992). In this study, a new method was applied to regulate rosetting and stem-extensibility to avoid the influences of the raising background. Using two types of plants grown under the same conditions, the growth and inner structure of shoots and roots could be compared without influences of cultural background.

\section{Materials and Methods}

The experiment was carried out from June to November 2004, using the progeny of the cultivar 'Ayanosakura' obtained by self-pollination. Some of the seeds were harvested 52 days after crossing in early July the previous year and thereafter, were ripened under $\operatorname{cool}\left(15^{\circ} \mathrm{C}\right)$ and dark conditions for three months to grow without rosetting after germinating. Others were harvested after ripening without exposure to a low temperature, for rosetting after germinating. Both types of seeds were sown in a 200-hole cell tray filled with vermiculite on June 22 and grown 
with one plant per cell by several early thinnings. Seedlings were grown in a glass house and transplanted into a $9 \mathrm{~cm}$-diameter polyethylene pot filled with clay loam ( $\mathrm{pH} 6.3$ ) blended at $30 \%$ (volume rate) with mixture of peat moss, compost, and Kanuma soil on September 8. On October 3, the seedlings were transplanted into larger polyethylene pots $(18 \mathrm{~cm}$ in diameter) without pulling them out of the original pots. They were grown in an opened-sided vinyl house in a test field. Manuring was applied using 2 kinds of liquid fertilizer $\left(\mathrm{A}: \mathrm{N} 7, \mathrm{P}_{2} \mathrm{O}_{5} 0\right.$, $\mathrm{K}_{2} \mathrm{O} 3$, and $\mathrm{B}: \mathrm{N} 1, \mathrm{P}_{2} \mathrm{O}_{5} 3, \mathrm{~K}_{2} \mathrm{O} 7$ ). The liquid fertilizers $A$ and $B$ were blended at $1: 1.2$ and diluted to $100 \mathrm{mg} \cdot \mathrm{L}^{-1}$ of nitrogen concentration. Each pot was applied adequately with the nutritional solution twice a week and watered sufficiently everyday. Five stem-extensional and five rosetted plants were gathered every few weeks from August 2 to November 16, and the roots were carefully washed with tap water. The characteristics of the aerial parts that were studied were shoot dry matter weight, length of the main stem (excluding peduncle), diameter of the hypocotyl, leaf number, length and width of the maximum leaf, number of lateral buds, and number of flower buds. Root dry matter weight, maximum root length, dimension of root branching, and number of thick first-branching roots ( $>1 \mathrm{~mm}$ in diameter) were also investigated. The inner structure of stems and roots was observed each sampling time. Cross sections 50 to $60 \mu \mathrm{m}-$ thick, cut with a Thoma's microtome, were enclosed with glycerin just after dyeing with phloroglucinol-alcohol solution and thick hydrochloric acid on a slide glass, and were immediately observed with an optical microscope.

\section{Results}

\section{Shoot growth}

Stem-extensional plants started the development of flower stalks in late October, ahead of flowering in midNovember. In contrast, rosetted plants developed no flower stalk and produced no flower. Despite the growth type, the shoot dry matter weights increased rapidly from two and a half months after seeding until mid-November, when the stem-extensional plants were in the flowering stage (Fig. 1a). Although the dry matter weight of rosetted plants increased at a slightly slower rate than that of the stem-extensional plants, the difference between shoot dry
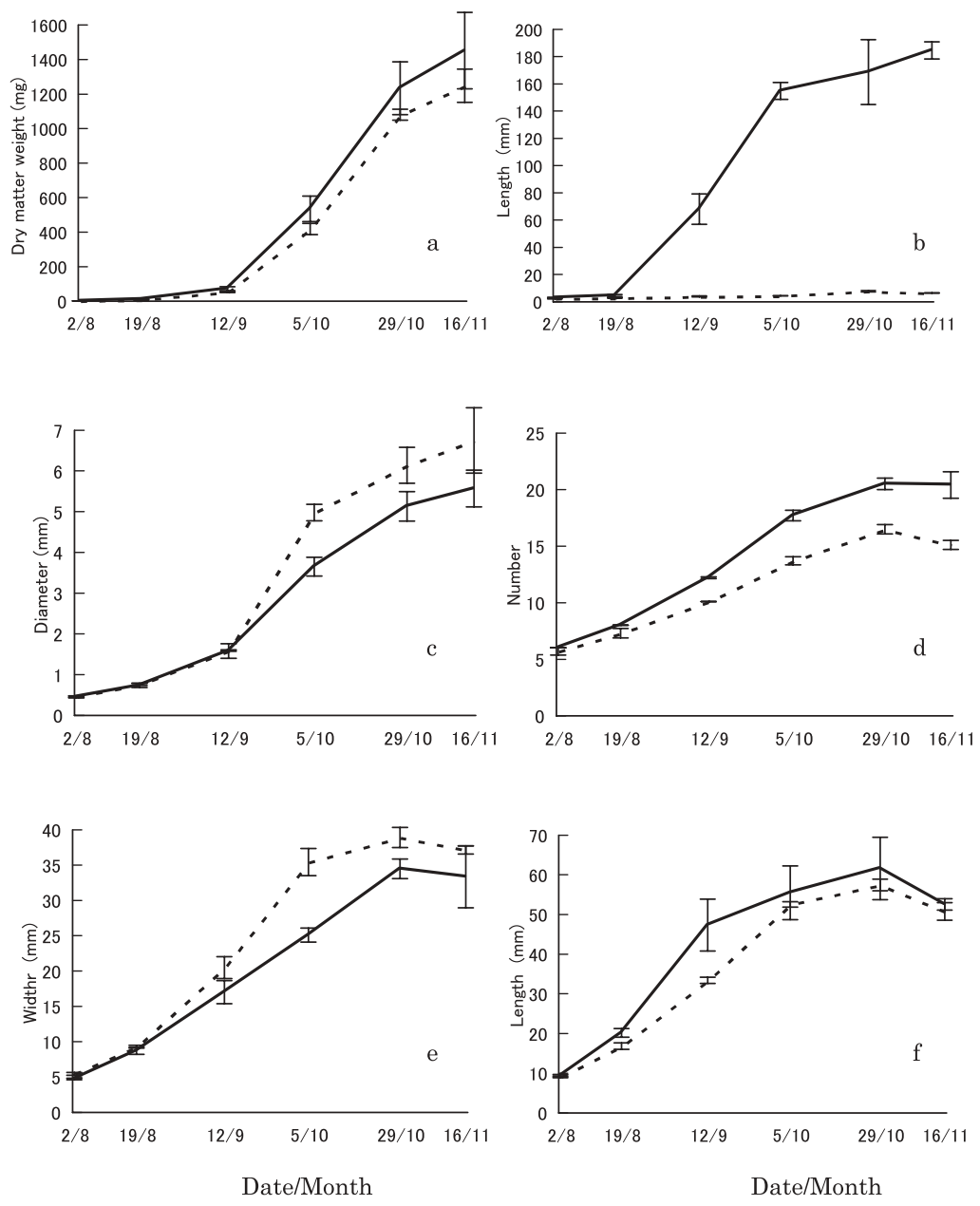

Fig. 1. Influences of rosetting on shoot growth.

a. total shoot weight per plant, b. main stem length, c. hypocotyl thickness, d. leaf number per plant, e. maximum leaf width, f. maximum leaf length. - stem-extensional plant. $\cdots \cdots$ rosetted plant. 
matter weights in both types of plants did not exceed 15\% throughout the growth period. However, each organ was marked by peculiar growth reactions, depending on the growth type. In particular, the main stem of the rosetted plants hardly elongated and remained extremely short (Fig. 1b). The stem length of the stem-extensional plants rapidly increased two months after seeding and reached about $20 \mathrm{~cm}$ by the flowering time, although the growth rate decreased after flower stalk development. On the contrary, the stems of rosetted plants did not grow over $1 \mathrm{~cm}$ in length throughout the growth period. The number of leaves of both types of plants increased until late October after germination; although they decreased slightly in mid-November because of the senescence and detachment of lower leaves (Fig. 1d). The stemextensional plants produced five more leaves than the rosetted plants by the time of flower stalk development. The difference in the number of leaves corresponded to about two nodes. The leaves of both rosetted and stemextensional plants nearly reached the maximal sizes by late October, when the stem-extensional plants were in the bolting period (Fig. $1 \mathrm{e}, \mathrm{f}$ ). The leaves of rosetted plants were rounder and thicker than those of stemextensional plants (Table 1). In both types of plants, the diameter of hypocotyls increased gradually during the early period of growth and rapidly after mid-September (Fig. 1c). The hypocotyls of the rosetted plants enlarged more actively after early October, and finally became thicker than those of the stem-extensional plants. Both types of plants formed auxiliary buds at the lower nodes after late September. Also, the stem-extensional plants formed secondary auxiliary buds. Finally, the rosetted plants had two fewer auxiliary buds than the stem- extensional plants. This difference seemed to depend on the formation of secondary auxiliary buds. The elongation of auxiliary buds was also observed to be strongly restrained in rosetted plants.

\section{Root growth}

Figure 2 depicts diachronic changes in several characteristics of roots. The root dry matter weight of both types of plants increased rapidly two and a half months after seeding; that of stem-extensional plants decreased somewhat in mid-November (flowering time) but that of rosetted plants continued to increase until mid-November. The difference between the root dry matter weight of stem-extensional and rosetted plants was barely recognizable from seedling to flowering stages. Concerning flowering time, however, the root dry matter weight of rosetted plants exceeded that of stem-extensional plants. The maximum root length of both types of plants was almost identical. The branching of roots reached the third or fourth dimension in both stem-extensional and rosetted plants. The rosetted plants formed evidently thicker firstbranch roots (more than $1 \mathrm{~mm}$ in diameter) than stemextensional plants (Table 1). According to observations during the final investigation, the roots of stemextensional plants grew downward and many roots grew out of the original pot through the bottom hole. However, the roots of rosetted plants tended to grow transversally and many roots were distributed in the original pot.

\section{Structural specificity of the stem and root}

Many large and small cavities were observed in the cortex of the stems and roots (Fig. 3). These structures were discovered in the basal part of hypocotyls on August

Table 1. Influences of rosetting on growth properties of the shoot and root.

\begin{tabular}{lcccc}
\hline \hline \multicolumn{1}{c}{ Sample } & $\begin{array}{c}\text { Number of } \\
\text { auxillary buds }^{z}\end{array}$ & $\begin{array}{c}\text { Thickness of leaf } \\
(\mu \mathrm{m})\end{array}$ & $\begin{array}{c}\text { Dimension of } \\
\text { branch root }\end{array}$ & $\begin{array}{c}\text { Number of first } \\
\text { branch roots }^{\mathrm{y}}\end{array}$ \\
\hline Stem-extensional plant & $9.2 \pm 0.7$ & $520.0 \pm 20.2$ & $3.4 \pm 0.3$ & $4.6 \pm 0.5$ \\
Rosetted plant & $7.4 \pm 0.3$ & $760.0 \pm 12.0$ & $3.6 \pm 0.3$ & $12.6 \pm 1.8$ \\
t-test & $\mathrm{NS}$ & $* *$ & $\mathrm{NS}$ & $* *$ \\
\hline
\end{tabular}

Investigated in mid-November. ${ }^{\mathrm{z}}$ The number per plant. ${ }^{\mathrm{y}}$ The number of thick branch roots $(>1 \mathrm{~mm}$ in diameter). Non-significant at $\mathrm{P}=0.05(\mathrm{NS})$ and significant at $\mathrm{P}=0.01(* *)$.
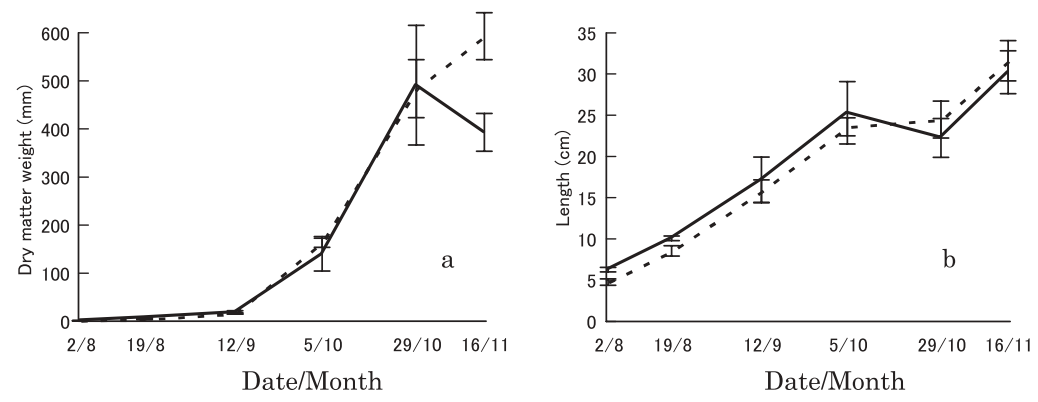

Fig. 2. Influences of rosetting on root growth. 

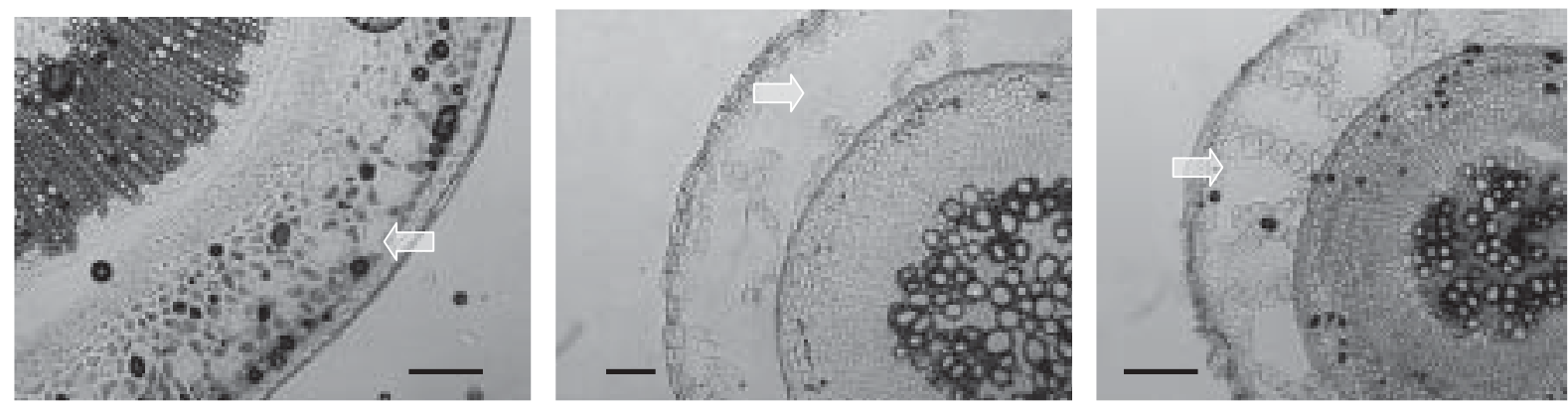

Fig. 3. Lysigenous aerenchyma (shown with arrow) formed in the cortex tissue of a stem and root (mid-November).

Left: basal part of stem (stem-extensional plant), Middle: middle part of primary root (stem-extensional plant), Right: basal part of thick branch root (rosetted plant). Bars $=0.23 \mathrm{~mm}$.

Table 2. Formation of lysigenous aerenchyma in the cortex tissue of the stem and root.

\begin{tabular}{clcc}
\hline \hline Date & \multicolumn{1}{c}{ Part } & Stem-extensional plant & Rosetted plant \\
\hline \multirow{2}{*}{21 July } & Hypocotyl & - & - \\
& Base of seminal root & - & - \\
& Top of seminal root & - & - \\
\hline \multirow{2}{*}{ Aug. } & Hypocotyl & ++ & + \\
& Base of seminal root & ++ & - \\
& Top of seminal root & ++ & ++ \\
& Hypocotyl & +++ & + \\
& Base of seminal root & +++ & - \\
& Top of seminal root & +++ & +++ \\
& Top of thick branch root & +++ & +++ \\
\hline \multirow{2}{*}{12 Sept. } & Hypocotyl & +++ & + \\
& Base of seminal root & +++ & + \\
& & + & Devent:
\end{tabular}

Three plants were observed. The growth stage on Aug. 2: 6 foliage leaves and 5-6 cm long roots. Development level: Cavity is unrecognizable in cortex tissue (-), small cavities are scattered in cortex tissue (+; Fig. 3, left), larger cavities integrated with small ones are scattered in cortex tissue (++; Fig. 3, right) and clusters of large cavities integrated occupy most of the cortex tissue (+++; Fig. 3, middle).

2 (about 40 days after sowing), and thereafter extended acropetally with the growth of main stems and the seminal and thick branch roots, accompanying the enlargement of the cavities. They became larger in roots than in stems (Fig. 3). The structures were observed not only in the rosetted plants but also in the stem-extensional plants; however, development in rosetted plants was somewhat delayed compared with that in stem-extensional plants (Table 2).

\section{Discussion}

It was previously confirmed that active elongation of the stem of Eustoma grandiflorum requires a specified temperature during ripening or in the early growth stage (Harbaugh et al., 1992; Ohkawa, 2003a; Pergola, 1992; Tanigawa et al., 2001). If the plants are not exposed to such a temperature in the life cycle, they retain the rosetted form. With rosetting, the stem hardly elongates, the flower bud does not differentiate, and the flower stalk does not develop. The rosetted plants used in this study also exhibited these peculiar phenomena. Rosetting is closely related to endogenous growth regulators. Specifically, the inhibition of gibberellin biosynthesis and the sensitivity of each organ to the regulator are considered to be major factors of rosetting (Hisamatsu, 2001). However, influences of rosetting on the growth of each organ, especially the root, are not yet clear. One difficulty has been the problem of growth background. Conventionally, rosetting has been induced by exposing a seedling to a high temperature, such as $25^{\circ} \mathrm{C}$ or above in mean temperature (Ohkawa, 2003a), whereas stem-extensibility has involved the exposure of a seedling or imbibed seed to such temperatures mentioned above (Harbaugh et al., 1992; Ohkawa, 2003a; Pergola, 1992; Tanigawa et al., 2001). These methods, however, are unsuitable for an exact comparison of the growth of rosetted and stemextensional plants, because thermal conditions during the germination and raising of seedlings could affect subsequent growth as a background. Therefore, the rosetted and stem-extensional plants in this study were grown under the same condition, using seeds provided each different thermal condition during the ripening 
period of the previous season, in order to remove influences of the cultural background. This method enabled a clear comparison of the growth of the two types of plants.

The shoot dry matter weight of the rosetted plants showed no distinguishable difference until the bolting time, as compared with that of stem-extensional plants, although their stem growth was extremely restrained. This was considered to be because rosetting did not strictly restrain the formation of leaves and lateral buds, thus promoting the thickening of stems and leaves and changing the leaves into a wide, round shape. Gibberellin is related to both shoot elongation and leaf thickening (Starman et al., 1990; Takesaki et al., 2004). However, the diverse changes in the characteristics of rosetted plants suggested that some other endogenous hormones were also involved in rosetting (Kato et al., 1992). The root dry matter weight of the rosetted plants increased throughout the growth period, maintaining a small difference from that of the stem-extensional plants until late October (bolting period). The maximum root length and branch root formation of the rosetted plants were almost identical to those of the stem-extensional ones. This suggested that the roots of Eustoma grandiflorum could actively grow even under the rosetted condition, perhaps because the rosetted plants continued vegetative growth. The root dry matter weight of the stem-extensional plants decreased after the bolting period. In rice plants, senescence and necrosis of roots are accelerated after the panicle formation stage (Inada, 1967). In Eustoma grandiflorum, also, the change into the reproductive phase in stemextensional plants might promote the senescence and detachment of roots, causing a quantitative root loss. Although root growth in rosetted plants was as active as that in stem-extensional plants, the thickening of roots and a change in the growth direction of roots were observed in the rosetted plants. These phenomena were also considered to be related to hormones (Miyazaki, 1998; Takahashi, 1998). The relationships between rosetting and root growth should be studied in more detail from a physiological viewpoint.

The many cavities observed in the cortex tissue of stems and roots were considered to be lysigenous lacunae produced by cell collapse. They developed well in both stems and roots, but the development was especially remarkable in roots. Cavities were formed in hypocotyls in the early stage of growth, extending acropetally with shoot and root growth. A similar structure in roots has been reported in paddy rice (Kono, 1979; Tatsumi, 1998) and tall-fescue grown under water stress (Ohtani et al., 1993). Such a structure is useful in compensating for a shortage of oxygen in the rooting zone, as lysigenous aerenchyma. Eustoma grandiflorum grows naturally in wetland (Yashiro, 1993) and exhibits a high tolerance to wetness (Imamura and Suto, 1998). This structure was also estimated to function as a aerenchyma. It was considered that Eustoma grandiflorum could acquire a high wetness tolerance by developing such a structure in roots and stems. The relationships between the structure and rosetting were not clear. However, some influences of rosetting were considered in its development because the development of the structure in the rosetted plants tended to be delayed compared with the stem-extensional plants. As ethylene is involved in the development of lysigenous aerenchyma (Ohtani et al., 1993), the relationships between ethylene and rosetting require further study in relation to other phenomena, such as the thickening of stem and roots, and the change in the growth direction of roots.

\section{Literature Cited}

Harbaugh, B. K., M. S. Roh, R. H. Lawson and B. Pemberton. 1992. Rosetting of Lisianthus cultivars exposed to high temperature. HortScience 27: 885-887.

Hisamatsu, T. 2001. Studies on the role of gibberellin biosynthesis in the control of growth and development in Matthiola incana (L.) R. Br. and Eustoma grandiflorum (Raf.) Shinn. Bull. Natl. Res. Inst. Vegetables, Ornamental Plants and Tea. 16: 79-134 (In Japanese with English summary).

Imamura, H. and K. Suto. 1998. Effect of the time on the test in rosette formation of Eustoma grandiflorum. Kyushu Agric. Res. 60: 182 (In Japanese).

Imamura, H., K. Suto and H. Ikeda. 2003. Influences of low temperatures and immature capsule on the degree of rosette formation in Eustoma grandiflorum. J. Japan. Soc. Hort. Sci. 72 (suppl. 2): 448 (In Japanese).

Inada, K. 1967. Physiological characteristics of rice roots, especially with the viewpoint of plant growth stage and root age. Bull. Natl. Inst. Agric. Sci. D16: 19-156 (In Japanese with English summary).

Kato, K., K. Tanaka and Y. Kamuro. 1992. Effects of (S)-(+)abscisic acid on bolting and flowering in Eustoma. J. Japan. Soc. Hort. Sci. 61 (suppl. 1): 478-479 (In Japanese).

Kono, K. 1979. Structure and physiology of roots. p. 163-178 (In Japanese). In: M. Shimizu (ed.). Morphogenesis of crops. Yokendo, Tokyo.

Miyazaki, A. 1998. Geotropism of root and phytohormons. p. 5658 (In Japanese). In: Editorial committee of encyclopedia of root (eds.). Encyclopedia of root. Asakurashoten, Tokyo.

Ohkawa, K. 2003a. Basic techniques for flowering control. p. 132 143 (In Japanese). In: K. Ohkawa (ed.). Practical technique of floral horticulture-Eustoma grandiflorum. Seibundo sinkosha, Tokyo.

Ohkawa, K. 2003b. Basic techniques for flowering control. p. 5867 (In Japanese). In: K. Ohkawa (ed.). Practical technique of floral horticulture-Eustoma grandiflorum. Seibundo Sinkosha, Tokyo.

Ohkawa, K., A. Kano, K. Kanematsu and M. Korenaga. 1991. Effects of air temperature and time on rosette formation in seedlings of Eustoma grandiflorum (Raf.) Shinn. Sci. Hort. 48: 171-176.

Ohkawa, A., M. Korenaga and T. Yoshizumi. 1993. Influences of temperature prior to seed ripening and at germination on rosette formation and bolting of Eustoma grandiflorum. Sci. Hort. 53: 225-230.

Ohkawa, A., M. Korenaga, T. Yoshizumi and A. Kano. 1992. Influences on Eustoma grandiflorum rosette formation by temperature prior to seed ripening and at germination. J. Japan. Soc. Hort. Sci. 61 (suppl. 1): 476-477 (In Japanese).

Ohkawa, A., T. Yoshizumi, M. Korenaga and K. Kanematsu. 1994. 
Reversal of heat-induced rosetting in Eustoma grandiflorum (Raf) with low temperatures. HortScience 29: 165-166.

Ohtani, I., Y. Takahashi and K. Ogino. 1993. Influences of soil environment on aerenchyma formation of pasture plants. Japan. J. Grassland Sci. 39 (suppl.): 51-52 (In Japanese).

Pergola, G. 1992. The need for vernalization in Eustoma russellianum. Sci. Hort. 51: 123-127.

Starman, T. W., J. Kelly and H. B. Pemberton. 1990. The influence of ancymidol on morphology, anatomy and chlorophyll levels in developing and mature Helianthus annuus leaves. Plant Growth Reg. 9: 193-200.

Takahashi, H. 1998. Root and ethylene. p. 147-149 (In Japanese). Editorial committee of encyclopedia of root (eds.). Encyclopedia of roots. Asakurashoten, Tokyo.
Takesaki, A., Y. Yoshida and M. Masuda. 2004. Leaf structure and photosynthetic properties in rosetting and bolting Eustoma plants. J. Japan. Soc. Hort. Sci. 73: 287-292 (In Japanese with English summary).

Tanigawa, T., Y. Kobayashi, H. Matsui and T. Kunitake. 2001. Effects of seedling age and high and low growth temperatures on bolting of Eustoma grandiflorum (Raf.) Shinn. Cultiv. J. Japan. Soc. Hort. Sci. 70: 201-509 (In Japanese with English summary).

Tatsumi, J. 1998. Morphology of root-aerenchyma. p. 14-16 (In Japanese). Editorial committee of encyclopedia of root (ed.). Encyclopedia of roots. Yokendo, Tokyo.

Yashiro, Y. 1993. Torukogikyo wo tsukurikonasu (In Japanese). Nobunkyo, Tokyo. 